\title{
KEHIDUPAN KARAWITAN KELOMPOK MARGO LARAS DI DESA MARGOMULYO KECAMATANTAYU KABUPATEN PATI
}

\author{
Andrianus Gigih Bayuaji ${ }^{1}$, Widodo ${ }^{2}$, \\ Pendidikan Seni Musik, Universitas Negeri Semarang \\ Email: gigih2505@gmail.com Email dosen: widodo bsejati@mail.unnes.ac.id
}

\begin{abstract}
ABSTRAK
Kelompok karawitan Margo Laras merupakan kelompok karawitan yang terkenal di Kabupaten Pati dan sekitarnya. Profesionalitas kelompok karawitan Margo Laras Pati terbangun oleh banyak hal, antara lain peran koordinator atau pemimpin kelompok, pemain atau penyaji, perangkat gamelan, dan intensitas latihannya. Kecakapan anggota kelompok Margo Laras dalam karawitan selain ditunjukkan oleh kemahirannya dalam memainkan ricikan gamelan dan vokal, juga tampak dalam memilih repertoar gending-gending sesuai konteksnya. Permasalahan yang dikaji adalah bagaimana kehidupan dan manajemen kelompok Margo Laras di Magotuhu Pati. Penelitian ini bertujuan untuk (1) mendeskripsikan peranan kelompok karawitan Margo Laras; (2) mendeskripsikan tentang manajemen kelompok karawitan Margo Laras. Dalam melakukan penelitian ini, metode yang digunakan adalah dengan kualitatif deskriptif. Hasil penelitian menunjukkan bahwa banyak peranan moral yang terkandung dalam kesenian karawitan. Peranan dalam masyarakat yaitu dalam mengiringi acara sedekah bumi pementasan wayang kulit dan upacara pernikahan adat Jawa. Kelompok Margo Laras terdiri dari anggota yang sudah terampil dalam bidang gamelan, serta dipimpin dan dilatih oleh Mustofa. Sarana prasarana berupa tempat latihan, seperangkat gamelan, dan kelengkapan pendukung. Peranan kelompok dalam masyarakat yaitu seringnya pentas dalam mengiringi pertunjukan wayang kulit maupun klenengan. Dalam satu pagelaran wayang kulit terdiri dari 3 babak yaitu pathet 6 , pathet 9, pathet manyura. Manajemen kelompok karawitan Margo Laras terdiri dari perencanaan, pengorganisasian, pergerakan, dan pengawasan. Latihan dilaksanakan secara ensidental pada menjelang pementasan atau saat adanya garap gending. Materi pelatihannya yaitu gending-gending pakeliran, garap, gending baru ciptaan dari Margo Laras, serta gending bawa dan langgam. Persiapan pementasan untuk sekedar berkumpul mencairkan suasana, makan bersama, cek sound perangkat gamelan, dan mempersiapkan kostum. Saran yang dapat peneliti berikan adalah perlu adanya struktur organisasi kelompok agar kinerja yang berhubungan dengan menejemen kelompok dapat lebih efektif, diadakan latihan rutin untuk melatih masyarakat yang ingin belajar karawitan, dukungan dari pemerintah untuk meningkatkan kualitas kelompok kesenian Margo Laras di Desa Margomulyo.
\end{abstract}

Kata kunci : kehidupan, peranan, manajemen, karawitan. 


\title{
MARGO LARAS KARAWITAN GROUP'S LIFE IN MARGOMULYO VILLAGE TAYU DISTRICT PATI REGENXY
}

\author{
Andrianus Gigih Bayuaji ${ }^{1}$, Widodo ${ }^{2}$, \\ Music Education Department, Universitas Negeri Semarang
}

Email: gigih2505@gmail.com Lecturer’s Email: widodo_bsejati@mail.unnes.ac.id

\begin{abstract}
Margo laras karawitan group is a karawitan group that is well known in Pati regency and surrounding. The professionalism of Margo Laras Pati karawitan group is built by many factors, like role of coordinator or group leader, player, gamelan instrument, and the intensity of practice. The proficiencies of the Margo Laras member's group in karawitan are showed by the proficiency in playing of gamelan's ricikan and sound, and also choosing the gending's repertory based on the context. The research of the problem are 1) to describe Margo Laras karawitan group's role 2) to describe the management of Margo Laras karawitan group. This research used descriptive ovalitative method. The result of the researched show that many moral valves are in karawitan art. The rule in society is to escort the alms earth event, the shadow graph performance, and Java custom wedding ceremony. Margo Laras group that consist of the expert members who play gamelan, and it is lead by a leader or practiced by a "Mustofa". The infrastructures are practice place, gamelan instrument, and the instrument support. The rule of group in society is to escort the shadow graph performance or "klenengan". In one shadow graph performance it consist of 3 stages, they are pathet 6 , pathet 9, pathet manyura. Margo Laras karawitan group's management consist of planning, organizing, movement and supervision. The practice is held incidentally by the time the performance or "garap gending" play. The material of practice consist of gending gending pakeliran, garap, new gending created by Margo Laras and gending bawa dan langgam. The preparations of performance are gathering or doing icebreaker, eating together, sound checking for gamelan instrument, and preparing the costum. The suggestion that the writer give are there must be a group organizational structure to make the performance that related to group management more effective, doing practice to society whom want to learn routinely, and there must supports from the government to improve the ovality of Margo Laras art group in Margomulyo village.
\end{abstract}

${ }^{1}$ Mahasiswa Jurusan Sendratasik Universitas Negeri Semarang Indonesia

${ }^{2}$ Dosen Jurusan Sendratasik Universitas Negeri Semarang Indonesia 


\section{PENDAHULUAN}

Pati merupakan salah satu kabupaten yang terletak di pantai utara pulau Jawa (pantura) bagian Timur di wilayah provinsi Jawa Tengah. Kabupaten ini memiliki potensi seni pertunjukan tradisi Jawa yang beragam. Beberapa jenis seni tersebut antara lain ketoprak, wayang kulit, tayub, barongan, karawitan, dan lainlain. Dalam setiap pertunjukannya, jenis-jenis seni tersebut selalu menggunakan dukungan karawitan Jawa. Karawitan berasal dari bahasa jawa rawit berarti rumit, berbelit-belit, tetapi rawit juga berarti halus atau indah. Martopangrawit (1975) berpendapat bahwa karawitan adalah sebagai seni suara vokal dan instrumen yang menggunakan nada-nada yang berlaras slendro dan pelog. Menurut catatan Dinas Pariwisata dan Kebudayaan Kabupaten Pati, di wilayah Pati terdapat sekitar 15 kelompok karawitan. Kelompok-kelompok karawitan itu didirikan selain untuk melayani pertunjukan jenis seni tradisi Jawa lainnya juga untuk memenuhi permintaan pentas mandiri dan mendukung rangkaian upacara adat Jawa. Salah satu kelompok karawitan di kabupaten Pati yang paling dikenal di lingkungan masyarakat Kabupaten Pati dan sekitarnya adalah Margo Laras. Kelompok karawitan Margo Laras paling sering melakukan pementasan karawitan untuk mengisi berbagai acara hajatan masyarakat. Hampir semua pementasan seni-seni tradisi di Kabupaten Pati dan sekitarnya menggunakan kelompok karawitan Margo Laras sebagai musik pendukungnya. Diantara banyak pertunjukan, jenis seni pertunjukan yang sering melibatkan kelompok karawitan ini adalah wayang kulit.

Profesionalitas kelompok karawitan Margo Laras Pati terbangun oleh banyak hal, antara lain peran koordinator atau pemimpin kelompok, pemain atau penyaji, perangkat gamelan, dan intensitas latihannya. Koordinator tim karawitan ini adalah Mustofa (48 tahun) seorang guru olahraga di Sekolah Dasar (SD) Negeri Gadu Kecamatan Margoyoso Kabupaten Pati, bertempat tinggal di desa Purworejo Kecamatan Margoyoso. Selain cakap dalam memainkan ricikan gamelan, ia juga mampu membuat kreasi gending-gending baru. Kecakapan anggota kelompok Margo Laras dalam karawitan selain ditunjukkan oleh kemahirannya dalam memainkan ricikan gamelan dan vokal, juga tampak dalam 
memilih repertoar gending-gending sesuai konteksnya. Pemilihan gendhing yang dimainkan dalam setiap pementasannya disesuaikan dengan fungsi pertunjukannya. Profesionalitas dan keterkenalan kelompok karawitan Margo Laras menarik perhatian untuk meneliti kehidupan dan manajemen kelompok kerawitan Margo Laras. Permasalahan yang dikaji adalah bagaimana peranan dan manajemen kelompok Margo Laras di Magotuhu Pati. Penelitian ini bertujuan untuk (1) mendeskripsikan peranan kelompok karawitan Margo Laras; (2) mendeskripsikan tentang manajemen kelompok karawitan Margo Laras.

\section{METODE PENELITIAN}

Pendekatan yang digunakan dalam penelitian "Kehidupan Karawitan Kelompok Margo Laras di Desa Margomulyo, Kecamatan Tayu, Kabupaten Pati” yaitu deskriptif kualitatif. Bogdan dan Taylor dalam Moleong (1990: 11) mendefinisikan pendekatan kualitatif sebagai prosedur penelitian yang menghasilkan data deskriptif berupa data tertulis atau lisan dari orang yang diamati Proses pengamatan dan identifikasi objek maupun subjek penelitian dilakukan dengan cara mendeskripsikan data yang didapat dari perilaku, perkataan lisan, maupun dokumentasi hasil pengamatan langsung ke dalam kata-kata atau kalimat dengan tujuan terpecahkannya semua permasalahan dalam penelitian ini. Data ditulis dalam bentuk deskripsi sehingga memiliki arti yang lebih kaya. Dalam mengumpulkan data, peneliti menggunakan teknik observasi, wawancara, dan telaah dokumen. Observasi dilakukan pada pelatihan kelompok karawitan Margo Laras di Desa Margomulyo, Kecamatan Tayu, Kabupaten Pati. Tujuan dari observasi dalam penelitian ini adalah untuk mengetahui metode, materi, dan evaluasi yang dilakukan pada pelatihan kelompok Margo Laras. Wawancara dalam penelitian ini dilakukan dengan beberapa nara sumber antara lain koordinator/pelatih dan anggota karawitan kelompok Margo Laras. Wawancara dengan koordinator/pelatih dilakukan untuk mengetahui pembentukan kelompok, kehidupan kelompok, peran kelompok dalam masyarakat, dan manajemen kelompok. Wawancara dengan anggota dilakukan untuk mengetahui jumlah pemain gamelan (pengrawit), sarana gamelan, latar belakang anggota, tingkat kesulitan proses pelatihan, dan pemahaman tentang materi yang diajarkan. Studi 
dokumen dalam penelitian ini mengkaji data seperti dokumen monografi Desa Margomulyo, repertoar gending latihan, foto pelatihan dan pementasan, serta rekaman audio visual saat pementasan. Pemeriksaan keabsahan data menggunakan criteria derajat kepercayaan dengan teknik triangulasi. Analisis data dilakukan melalui 3 tahap, yaitu: (1) reduksi data, (2)display/penyajian data dan (3) mengambil kesimpulan lalu diverifikasi.

\section{HASIL PENELITIAN DAN PEMBAHASAN}

\section{Kelompok Karawitan Margo Laras}

Margo Laras adalah salah satu nama kelompok karawitan yang ada di Desa Margomulyo, Kecamatan Tayu, Kabupaten Pati. Kelompok ini merupakan kelompok karawitan yang cukup terkenal di Kabupaten Pati dan sekitarnya. Margo Laras juga sering melakukan pementasan kariwitan untuk mengisi berbagai acara hajatan. Jenis seni pertunjukan yang sering melibatkan kelompok karawitan ini adalah wayang kulit. Beberapa dalang wayang kulit dari Kabupaten Pati sering menggunakan jasa kelompok karawitan ini untuk mendukung pertunjukannya.

Kelompok karawitan Margo Laras terbentuk tahun 1990 atas inisiatif Yarji yang merupakan seorang pengrawit gamelan yang tinggal di Desa Margomulyo. Inisiatif ini muncul sejak Desa Margomulyo membeli seperangkat gamelan lengkap pelog dan slendro yang ditempatkan di Gubuk Desa. Hal ini ditujukan untuk memajukan kesenian karawitan di Desa Margomulyo. Sejak saat itu dimulai pelatihan rutin yang dipimpin oleh Yarji. Seiring berjalannya waktu, banyak warga dari luar Desa Margomulyo yang ikut dalam latihan karawitan tersebut. Antusias warga terhadap pelatihan karawitan saat itu sangat baik, sehingga latihan karawitan rutin diadakan dua kali dalam sepekan yaitu, hari Kamis dan Sabtu malam pukul 19.00-22.00 WIB.

Yarji dan anggotanya memberikan nama Margo Laras untuk sebutan kelompok karawitannya. Margo berarti jalan atau bisa juga diartikan sebagai tempat awal terbentuknya kelompok tersebut yaitu Desa Margomulyo. Laras berarti rasa atau bisa juga disebut nada dan tangganada dalam dunia karawitan. 
Jika digabungkan, Margo Laras bisa diartikan sebuah nada-nada indah dalam karawitan yang berasal dari Desa Margomulyo.

\section{Peranan Kelompok Karawitan Margo Laras Dalam Masyarakat}

Peranan kelompok karawitan Margo Laras dalam masyarakat antara lain sebagai pengiring wayang kulit dan klenengan dalam berbagai acara sedekah bumi dan upacara adat pernikahan yang berada di berbagai daerah kabupaten Pati maupun luar Kabupaten Pati. Peranan kelompok karawitan dalam masyarakat antara lain seringnya pentas kelompok ini dalam mengiringi pertunjukan wayang kulit di berbagai acara-acara seperti sedekah bumi dan lainnya. Salah satu pementasan iringan wayang kulit kelompok Margo Laras yaitu di acara sedekah bumi Desa Puncel pada tanggal 20 Agustus 2016. Kelompok Margo Laras menjadi pengiring wayang kulit bersama Dalang Ki Kunarto dari Jepara.

Setelah jalannya ritual sedekah bumi pada pagi sampai siang hari, kemudian malam harinya dilanjutkan dengan acara hiburan pertunjukan wayang kulit. Pementasan kelompok karawitan Margo Laras dalam iringan wayang kulit dimulai pada malam hari pukul 20.00 WIB. Dalam satu lakon biasanya lama pertunjukkan sekitar 7-8 jam atau yang biasa disebut semalam suntuk. Biasanya untuk satu pagelaran wayang kulit terdiri dari 3 babak yaitu Babak I dari mulai hingga gara-gara menggunakan pathet 6 (nem), babak II adegan gara-gara menggunakan pathet 9 (sanga) dan babak III dari selesainya gara-gara hingga tancep kayon yang menggunakan pathet manyura.

Peranan kelompok karawitan Margo Laras dalam masyarakat salah satunya yaitu sajian klenengan dalam acara nikahan masyarakat. Salah satu pementasan klenengan kelompok Margo Laras yaitu di acara pernikahan Sumaryono dan Nindrawati pada tanggal 23 september di Desa Sumberrejo. Pernikahan atau perkawinan adat jawa melambangkan pertemuan antara pengantin wanita yang cantik dan pengantin pria yang gagah dalam suatu suasana yang khusus sehingga pengantin pria dan pengantin wanita seperti menjadi raja dan ratu sehari. Klenengan merupakan pertunjukan seni karawitan dengan menampilkan gending-gending karawitan jawa dan garap di dalamnya. Pementasan klenengan dibuka dengan sajian ladrang wilujeng, serta memainkan 
berbagai gending pahargyan lainya, sambil memenuhi permintaan gending dari tamu yang datang.

\section{Manajemen Kelompok Margo Laras}

Manajemen kelompok Margo Laras meliputi perencanaan, pengorganisasian, pergerakan, dan pengawasan.

\section{Perencanaan}

Pengelolaan sebuah organisasi tidak lepas dengan adanya sebuah perencanaan terlebih dahulu. Perencanaan dibuat sebelum melakukan pengorganisasian, penggerakan dan pengawasan. Stoner (dalam T.Hani Handoko 2003: 8) mengemukaka manajemen adalah proses perencanaan, pengorganisasian, pengarahan, dan pengawasan usaha-usaha para anggota organisasi dan penggunaan sumber daya organisasi lainnya agar mencapai tujuan organisasi yang telah ditetapkan. Demikian juga kelompok karawitan Margo Laras, dengan adanya perencanaan dapat memberikan satu gambaran dan arah serta petunjuk tentang langkah-langkah yang perlu diambil. Perencanaan meliputi perencanaan tujuan, latihan dan materi. Tujuan kelompok menurut Mustofa yang menjabat sebagai koordinator sekaligus pelatih kelompok karawitan Margo Laras antara lain mempererat rasa persaudaraan dan menumbuhkan rasa kekeluargaan antara anggota, menumbuhkan rasa menghargai dan melestarikan gamelan Jawa sebagai warisan budaya yang adiluhung, serta menjadikan pribadi yang kreatif dan produktif. Selain itu, dibentuknya kelompok Karawitan Margo Laras juga dilaksanakan untuk tujuan pementasan, baik yang diundang oleh perorangan maupun instansi pemerintah atau swasta.

Pelatihan karawitan dilakukan pada awal-awal pembentukan kelompok, sedangkan pelatihan insidental dilakukan setelah anggota kelompok relatif menguasai garap gending. Dewasa ini pelatihan kelompok karawitan tersebut sering dilakukan secara ensidental pada menjelang pementasan atau saat adanya garap gending. Materi latihan tidak hanya mencakup gending pakeliran wayang kulit saja. Ada juga gending buatan kelompok Margo Laras, serta gendinggending bawa dan langgam. Materi latihan biasanya menyesuaikan dengan garap gending baru yang sudah dipilih atau dibuat oleh Mustofa. Untuk gending 
pakeliran biasanya menyesuaikan dengan permintaan dalang wayang. Contoh beberapa materi pelatihan gending pakeliran antara lain Ayak-ayak Patalon kalajengaken Srepeg terus Sampak, serta materi Garap Seno Ngumbara. Beberapa gending ciptaan Margo Laras antara lain, Langgam Pamilihing Ati, Pl. Nem, Langgam Sila 5, P.Nem, Repertoar gending langgam kelompok karawitan Margo Laras anara lain Caping Nggunung, Setya Tuhu, Wuyung Laras, Ngimpi.

\section{Pengorganisasian}

Pengorganisasian dapat diartikan sebagai proses pengelompokan orangorang, alat dan pembagian tugas serta wewenang sehingga sebuah organisasi dapat mencapai tujuan yang diharapkan. T.Hani Handoko (1986: 76) merumuskan organisasi merupakan wadah kerjasama sekelompok orang dalam rangka mencapai tujuan yang telah dirumuskan bersama. Pengorganisasian bertugas mengurusi jadwal latihan, pentas, pengelolaan keuangan, penerimaan anggota baru, pengkondisian alat. Pengorganisasian kelompok Margo Laras hanya terdiri dari ketu dan kelompok. Ketua karawitan kelompok Margo Laras adalah Mustofa berusia 48 tahun, dan bekerja sebagai guru olahraga di SD Negeri 1 Gadu. Kelompok karawitan Margo Laras belum memiliki struktur organisasi tetap. Tidak adanya kepengurus dalam kelompok karawitan ini menjadikan Mustofa untuk mengkoordinir setiap kegiatan Margo Laras. Kegiatan yang dikoordinir antara lain, menerima tawaran pentas dari masyarakat, menginformasikan latihan dan pementasan ke seluruh anggota, manajemen keuangan, memberi materi gending berupa notasi lagu pada anggota, memimpin jalannya setiap latihan dan pertunjukan, serta mempersiapkan hal-hal yang dibutuhkan saat pementasan atau pertunjukkan.

Para anggota karawitan kelompok Margo Laras keseluruhan mencakup pengrawit, sinden, dan wiraswara berjumlah 17 orang yang berasal dari berbagai daerah. Mereka yang menjadi anggota kelompok Margo Laras merupakan pemain yang sudah terampil dalam memainkan ricikan gamelan. Kemampuan karawitan pada umumnya diperoleh secara otodidak, dan oleh masyarakat setempat disebut pengrawit alam. Mereka senang berlatih dan pentas bersama kelompok karawitan lain di Kabupaten Pati, karena kecintaanya pada kesenian karawitan Jawa. 
Walaupun terbentuk melalui sistem pendidikan informal, namun karena dorongan kecintaan yang besar terhadap karawitan Jawa, seringnya berlatih dengan kelompok karawitan maupun mandiri, seringnya berpentas, maka pada akhirnya mereka memiliki kemampuan karawitan yang baik. Pekerjaan utama anggota kelompok karawitan Margo Laras sebagian besar adalah petani, namun ada beberapa yang berprofesi sebagai PNS seperti, Mustofa, Sumar, dan Sundari.

\section{Pergerakan}

Penggerakan adalah tindakan yang menyebabkan sebuah organisasi dapat berjalan, sehingga semua personil yang terlibat dalam sebuah organisasi harus berupaya ke arah sasaran yang hendak dituju agar sesuai dengan perencanaan manajerial. Penggerakan dalam manajemen kelompok karawitan Margo Laras adalah proses pementasan kelompok karawitan Margo Laras. Kelompok karawitan Margo Laras paling sering melakukan pementasan karawitan untuk mengisi berbagai acara hajatan masyarakat dalam bentuk iringan wayang dan klenengan. Hampir semua pementasan seni-seni tradisi di Kabupaten Pati dan sekitarnya menggunakan kelompok karawitan Margo Laras sebagai musik pendukungnya. Diantara banyak pertunjukan, jenis seni pertunjukan yang sering melibatkan kelompok karawitan ini adalah wayang kulit.

Konsep pementasan seperti gending apa saja yang akan dimainkan sudah dipersiapkan saat proses latihan. Materi pementasan menyesuaikan permintaan Dalang yang disampaikan kepada Bapak Mustofa, kemudian Beliau yang menyampaikan kepada anggotanya dan menyiapkan notasinya saat latihan. Pementasan kelompok Margo Laras lebih sering digunakan untuk iringan wayang kulit. Biasanya pementasan wayang kulit dimulai pada malam hari pukul 20.00 WIB. Para anggota kelompok Margo Laras datang lebih awal 1 sampai 2 jam sebelum pementasan untuk sekedar berkumpul mencairkan suasana, makan bersama, cek sound perangkat gamelan, dan mempersiapkan kostum. Persiapan perangkat gamelan biasanya sudah disiapkan dan ditata oleh juru gamelan pada siang hari sebelum pementasan. Kemudian sore harinya anggota kelompok Margo Laras melakukan cek sound perangkat gamelan dengan mengecek satu persatu 
gamelan, kemudia dimainkan secara bersama-sama dengan tujuan memperoleh hasil sound out yang bagus saat pementasan.

\section{Pengawasan atau Evaluasi}

Pengawasan adalah kegiatan yang dilakukan oleh ketua kelompok Margo Laras dalam mengupayakan agar kegiatan-kegiatan yang dilakukan kelompok Margo Laras sesuai dengan perencanaan yang telah ditentukan. Adanya pengawasan ini dimaksudkan untuk mengetahui hambatan-hambatan, kesalahankesalahan dan kegagalan sehingga dapat segera dicari pemecahannya. Pengawasan yang dilakukan oleh ketua kelompok Margo Laras yaitu dengan melihat secara langsung dari proses latihan anggota kelompok Margo Laras sampai dengan pementasan dan bagaimana persiapan para anggota kelompok Margo Laras dari segi fisik maupun mental, kematangan materi lagu yang akan dibawakan kelompok Margo Laras. Hal-hal yang dilakukan kelompok Margo Laras setelah pementasan selesai yaitu diadakannya; evaluasi pementasan, serta mengecek dan membereskan perlengkapan pentas dan peralatan gamelan. Evaluasi pementasan dilakukan dengan mengumpulkan seluruh anggota kelompok, dan mereka satu persatu mengutarakan hal-hal yang dirasa kurang menurut pribadi masing-masing. Evaluasi bertujuan untuk mengetahui kekurangan apa saja yang telah dilakukan saat pementasan berlangsung.

\section{SIMPULAN}

Berdasarkan hasil penelitian dapat disimpulkan bahwa kehidupan kelompok karawitan Margo Laras sangat dekat dengan masyarakat, dan banyak peranan moral yang terkandung dalam kesenian karawitan dalam kehidupan masyarakat sehari-hari. Kelompok ini sering melakukan pementasan karawitan sebagai pengiring wayang kulit dan klenengan untuk mengisi sedekah bumi dan upacara adat pernikahan dalam masyarakat. Masyarakat sangat antusias untuk mengundang kelompok Karawitan Margo Laras dalam suatu acara yang diadakannya. Seni karawitan dapat berfungsi sebagai sarana upacara, sarana hiburan, sarana komunikasi, dan melestarikan kesenian karawitan dan memperkenalkan kepada generasi muda. 
Manajemen kelompok karawitan Margo Laras terdiri dari perencanaan, pengorganisasian, pergerakan, dan evaluasi. Perencanaan memberikan gambaran yang akan dicapai oleh kelompok Margo Laras. Pengorganisasian hanya terdiri dari ketua dan anggota saja,karena kelompok Margo Laras. Pelatih sekaligus koordinator kelompok ini adalah Mustofa, yang bertugas dalam setiap proses pelatihan dan manajemen kelompok. Anggota terdiri dari 17 orang yang berasal dari daerah berbeda-beda dan sudah mahir dalam memainkan ricikan gamelan. Penggerakan dalam manajemen kelompok karawitan Margo Laras adalah proses pementasan kelompok karawitan Margo Laras dalam mengiringi pementasan wayang kulit. Pengawasan yang dilakukan oleh ketua kelompok Margo Laras yaitu dengan melihat secara langsung dari proses latihan anggota kelompok Margo Laras sampai dengan pementasan dan bagaimana persiapan para anggota kelompok Margo Laras dari segi fisik maupun mental, kematangan materi lagu yang akan dibawakan kelompok Margo Laras.

\section{SARAN}

Berdasarkan hasil penelitian, saran yang diberikan guna meningkatkan pelatihan karawitan Margo Laras yaitu.

1. Perlu adanya struktur organisasi kelompok agar kinerja yang berhubungan dengan menejemen kelompok dapat lebih efektif dan tidak hanya dibebankan pada koordinator/pelatih saja.

2. Diadakan latihan rutin untuk terus mengasah ketrampilan anggota kelompok, serta mengadakan pelatihan pada masyarakat.

3. Perlunya dukungan dari pemerintah daerah untuk meningkatkan kualitas kelompok kesenian Margo Laras di Desa Margomulyo.

\section{DAFTAR PUSTAKA}

Ganap, V. (2011). Pengaruh Portugis pada Musik Keroncong (Portuguese Influence to Kroncong Music). Harmonia: Journal Of Arts Research And Education, 7(2). doi:http://dx.doi.org/10.15294/harmonia.v7i2.753

Handoko, Hani. 1986. Manajemen. Yogyakarta: BPFE. 
Handoko, Hani. 2003. Manajemen edisi 2. Yogyakarta: BPFE

Moleong, Lexy J. 1990. Metodologi Penelitian Kualitatif. Bandung: Remadja Rosda Karya CV.

Pangrawit, Marto. 1975. Pengetahuan karawitan. Surakarta: ASKI Surakarta

Widjajadi, R. (2011). MENULUSURI SARANA PENYEBARAN MUSIK KRONCONG (EXPLORING A DISSEMINATION MEDIUM OF KERONCONG MUSIC). Harmonia: Journal Of Arts Research And Education, 6(2). doi:http://dx.doi.org/10.15294/harmonia.v6i2.721

Widodo. (2015). Laras in Gamelan Music's Plurality. Harmonia: Journal Of Arts Research And Education, 15(1), 34-45. doi:http://dx.doi.org/10.15294/harmonia.v15i1.3695 